\title{
New Editor-in-Chief for BJPP
}

am delighted to be the new Editor-in-Chief of the Brazilian Journal of Plant Physiology (BJPP) since January 2012. The main reason for me to be heading BJPP is a simple statement - to spread Brazilian research enlightenment on plant physiology worldwide. During the past decade, the transformation of BJPP was really stunning, and I deeply admire the past Editors who enabled this. Based on their work, my perspective for the future of BJPP is to keep the two plates of the balance under a progressive zone. Using the successful experiences held in the past is a glorious point, but the future should be traced with policies that will allow BJPP to improve in quality. And I am grateful to announce that Dr. Rafael Vasconcelos Ribeiro was named as the new Assistant Editor, and Dr. Mara de Menezes Assis Gomes as the head of the Editorial Office. The editorial process would not be possible without the volunteer and hard work of our board of Associate Editors, composed by scientists from several countries. We have in mind that attracting elite plant physiologists to publish in BJPP is a welcome effort. This will surely enhance the number of citations and lead the journal to be more engaged with new knowledge and insights concerning plant physiology. And to support the advances of BJPP, innovations and new ideas must emerge and be put into practice to ensure the high quality of the publications and to be responsive to changing world perspectives. Based on these ideas, the Editorial Board will concentrate efforts in order for the journal to be indexed by the Institute for Scientific Information - Journal of Citation report (ISI/JCR). Therefore, publishing the issues on time is mandatory. We have made some structural and organizational changes in the journal that will result in a more systematic work in the editorial process. For example, we adopted an anti-plagiarism system (the same used by the American Society of Plant Biologists and its associated journals) which will improve the transparency and the accuracy of the publications. In addition, BJPP started the process of editing and publishing their manuscripts with a specialized editorial company, thus becoming faster and more efficient. It is clear for us that optimizing the ability to publish is our main focus, and for that reason the average time from submission to the first decision is only 5 days. The new initiatives we have in mind in order for BJPP to become more proactive are: i. Using an electronic system for manuscript submission; ii. Creating an exclusive website in which policies, publications, data on submission and updated information can be available for authors and readers; iii. Recovering the history of BJPP all the papers that have been published since 1989 will be electronically available in our future website; iv. Making a version of the whole content of BJPP for tablets.

Towards this end, much work is necessary and the whole Editorial Board is committed to doing their best.

Ricardo Bressan-Smith Editor-in-Chief, BJPP 
